Artigo original

Hegemonia - Revista Eletrônica de Relações Internacionais do Centro Universitário Unieuro

ISSN: 1809-1261

UNIEURO, Brasília, número 20, Janeiro-Junho de 2016, pp. 120-147.

Recebido em: 22/10/2016

Avaliado em: 12/11/2016

Aprovado em: 10/12/2016

\title{
Impactos do Bolsa Família sobre a Pobreza e a
}

\section{Desigualdade no Nordeste}

\author{
Isabela D’Loan Silva Leão, ${ }^{1}$ Tito Belchior Silva Moreira ${ }^{2}$ e George Cunha ${ }^{3}$
}

Resumo: Este artigo avalia em que medida os benefícios monetários do programa Bolsa Família contribuíram para a redução da pobreza e da desigualdade da renda domiciliar per capita na região nordeste entre 2004 e 2011, a partir dos dados da Pesquisa Nacional por Amostra de Domicílios (PNAD). Utiliza-se a metodologia proposta por Hoffman $(2004,2005)$ de decomposição do índice de Gini conforme parcelas do rendimento domiciliar per capita, a fim de analisar a contribuição desses componentes para a redução da desigualdade no Nordeste. Os resultados indicaram queda no índice de Gini da região, de 0,5814 em 2004 para 0,5440 em 2011. As maiores contribuições para essa redução partiram das aposentadorias e pensões e da renda derivada do trabalho. O Programa Bolsa Família, por sua vez, foi responsável por $11 \%$ da redução do Gini, revelando seu crescimento em termos de participação no rendimento. $\mathrm{O}$ impacto sobre a pobreza também foi expressivo. Dada a linha de pobreza de $\mathrm{R} \$ 140,00$ per capita, observou-se queda de $22,40 \%$ da proporção de pobres no período em análise, número esse que representa mais de 22 milhões de pessoas.

Palavras chave: Pobres, aposentadorias, pensões, PNAD, Gini.

Abstract: This article assesses the extent to which monetary benefits from the family scholarship program contributed to the reduction of poverty and inequality in per capita household income in the Northeast between 2004 and 2011, based on the data of the National Sample Survey (PNAD). We use the methodology proposed by Hoffman (2004, 2005) regarding to decomposition of the Gini index as partitions of household income per capita in order to analyze the contribution of these components to the reduction of inequality in the Northeast. The family scholarship program, in turn, was responsible for $11 \%$ of the reduction in Gini index, revealing its growth in terms of participation in income. The impact on poverty was also significant. Given the poverty line of $\mathrm{R} \$ 140.00$ per capita, we observed a decrease of $22.40 \%$ in the proportion of poor in the period, which represents more than 22 million people.

Keywords: Poor, retirement, pension, PNAD, Gini.

\footnotetext{
1 Economista; Graduada; SGAN 916, Departamento de Economia, W5 - CEP: 70.790-160; isabeladloan@gmail.com.

2 Economista; Doutor; Departamento de Economia da Universidade Católica de Brasília; SGAN 916, Departamento de Economia, W5 - CEP: 70.790-160; tito@pos.ucb.br.

${ }^{3}$ Economista; Doutor; Departamento de Economia da Universidade Católica de Brasília; SGAN 916, Departamento de Economia, W5 - CEP: 70.790-160; george@ucb.br.
} 
Artigo original

Hegemonia - Revista Eletrônica de Relações Internacionais do Centro Universitário Unieuro

ISSN: 1809-1261

UNIEURO, Brasília, número 20, Janeiro-Junho de 2016, pp. 120-147.

\section{INTRODUÇÃO}

Atualmente, mais de 16 milhões de brasileiros vivem (ou sobrevivem) com até $\mathrm{R} \$ 70,00$ por mês. Essa precariedade de renda, obviamente, deixa esses indivíduos em situação de alta vulnerabilidade socioeconômica. Nesse contexto, surgem as ações sociais afirmativas com o papel de contrabalancear, e até reverter, este quadro, permitindo o avanço no sentido de disseminar, mais equanimemente, o desenvolvimento nacional.

Dentre essas ações está o Bolsa Família, programa de transferência direta de renda de maior cobertura na rede de proteção social brasileira. Segundo informações do Ministério do Desenvolvimento Social e Combate à Fome (MDS), eram 6,57 milhões de famílias beneficiárias em 2004 e, em 2011, somavam-se 13,35 milhões.

O Programa foi criado com o duplo objetivo de combater a pobreza no curto prazo, via transferência direta de renda, e de aumentar o incentivo à acumulação de capital humano no longo prazo, através de condicionalidades referentes ao acesso básico à saúde e à educação, buscando, assim, estimular a emancipação sustentada das famílias que vivem em situação de pobreza e extrema pobreza.

Em 2011, o Nordeste reunia a maior quantidade de benefícios pagos pelo Programa em nível nacional, equivalente a $51,2 \%{ }^{4}$, fato justificável pelo alto grau de pobreza entre seus habitantes. Dados do Ipea Data mostram que em 2004, por exemplo, ali se concentrava 48\% da população extremamente pobre do País.

Deste modo, o presente estudo tem como objetivo analisar em que medida os benefícios monetários do programa Bolsa Família contribuíram para a redução da pobreza e da desigualdade da renda domiciliar per capita naquela região, entre 2004 e 2011, a partir dos dados da Pesquisa Nacional por Amostra de Domicílios (PNAD) dos respectivos anos.

\footnotetext{
${ }^{4}$ Ministério do Desenvolvimento Social e Combate à Fome (MDS).
} 
Artigo original

Hegemonia - Revista Eletrônica de Relações Internacionais do Centro Universitário Unieuro

ISSN: 1809-1261

UNIEURO, Brasília, número 20, Janeiro-Junho de 2016, pp. 120-147.

A contar desta introdução, este artigo está organizado em seis seções. A seção dois visita a

literatura sobre o objeto de estudo; a seguinte apresenta os dados de forma mais detalhada. A quarta seção explica os pontos essenciais relacionados à metodologia. Na quinta seção são expostos os principais resultados. Por fim, a última seção sumariza as conclusões do trabalho.

\section{REVISÃO DA LITERATURA}

No Brasil, a implementação de políticas sociais destinadas a transferir renda aos mais pobres iniciou-se ainda no período militar, em 1970. Porém, não alcançaram significativa repercussão, devido à cobertura limitada da sua população alvo, que eram os idosos e portadores de deficiência incapazes de garantir seu sustento. (Rocha, 2011)

Com o advento da Constituição Federal de 1988, houve um redimensionamento das políticas públicas estimuladoras do desenvolvimento social. O constituinte originário procurou assegurar a dignidade da pessoa humana (CF, Art. $1^{\circ}$, III), vinculando o Estado a garantir aos cidadãos pelo menos as condições básicas para uma existência digna, objetivando, assim, erradicar a pobreza e reduzir as desigualdades sociais e regionais (CF, Art. $3^{\circ}$, III) Desta maneira, criou-se o espaço definitivo para programas assistencialistas focalizados nos mais pobres, com o objetivo de cumprir aquilo que a Constituição determinava.

Durante a década de 90, houve esforços governamentais para dar execução a alguns programas de transferência de renda com objetivos específicos. Soares et al. (2006) destaca as características de cada um desses programas criados pelo Governo Federal, a saber: o Bolsa Escola (que já vinha sendo executado em alguns municípios brasileiros), o Auxílio Gás, o Programa de Erradicação do Trabalho Infantil (PETI) e o Bolsa Alimentação.

O Bolsa Escola concedia um benefício monetário às famílias com renda per capita mensal de até meio salário mínimo que mantivessem seus filhos matriculados e frequentando a escola. $\mathrm{O}$ 
Artigo original

Hegemonia - Revista Eletrônica de Relações Internacionais do Centro Universitário Unieuro ISSN: 1809-1261

UNIEURO, Brasília, número 20, Janeiro-Junho de 2016, pp. 120-147.

Auxílio Gás compensava famílias de baixa renda pelo fim do subsídio no preço do gás de cozinha, com um auxílio de $R \$ 7,50$ ao mês, pago bimestralmente em parcelas de $R \$ 15,00$. $O$ PETI tinha como público alvo famílias com renda per capita de até meio salário mínimo, se em sua composição houvesse crianças de 7 a 15 anos envolvidas em trabalhos insalubres, penosos ou degradantes. Caso a família firmasse o compromisso de manter seus filhos longe do trabalho e frequentando a escola (era exigido presença mínima de 75\%), estaria apta a receber o auxílio. Por fim, o Bolsa Alimentação atendia famílias com renda mensal de até meio salário mínimo per capita, com crianças de zero a sete anos, e/ou que possuíssem gestantes e mães no período de amamentação. O benefício tinha como finalidade combater a desnutrição entre estes membros do grupo familiar.

Segundo Rocha (2011), foi criado em 2001, ainda no governo de Fernando Henrique Cardoso, o Cadastro Único para Programas Sociais do Governo Federal (CadÚnico), que objetivava a coordenação e controle da focalização dos programas de transferência, que estavam, cada um, atrelados a algum organismo governamental distinto, com um cadastro específico, embora destinados ao mesmo público. Porém, a iniciativa foi de pouco sucesso, visto que a implementação do CadÚnico foi lenta e pouco eficiente.

Com o início do governo Lula, Rocha (2011) ressalta que houve significativas iniciativas para modificar o meio como as políticas de transferência de renda chegavam à população de baixa renda. Em 2003 foi criado o Cartão Alimentação (denominado Fome Zero), com assistência financeira de $\mathrm{R} \$ 50,00$ mensais às famílias com renda per capita inferior a meio salário mínimo. O Programa tinha como objetivo complementar a renda dos mais pobres para a compra de alimentos. O Cartão Alimentação trouxe como novidade a elegibilidade ao benefício a todas as famílias que tinham renda per capita de até 1/4 do salário mínimo.

Rocha (2011) observa ainda que havia por parte do governo o objetivo de unificar os programas de transferência de renda até então existentes. Neste contexto, o Cartão Alimentação 
Artigo original

Hegemonia - Revista Eletrônica de Relações Internacionais do Centro Universitário Unieuro

ISSN: 1809-1261

UNIEURO, Brasília, número 20, Janeiro-Junho de 2016, pp. 120-147.

foi relançado sob a denominação "Bolsa Família". Houve alteração das regras de elegibilidade do programa, que passou a vigorar desatrelado do salário mínimo e com benefícios variáveis, que seriam calculados de acordo com a renda e a composição familiar.

Deste modo, em 2003 foi criado o Programa Bolsa Família (PBF), unificando os programas já existentes Bolsa Escola, Bolsa Alimentação, Auxílio Gás e Cartão Alimentação (Fome Zero) $)^{5}$ O público alvo do PBF são as famílias em situação de pobreza e de extrema pobreza, inscritas no CadÚnico. O Programa tem como característica principal a transferência direta de renda sob o cumprimento de condicionalidades, ou seja, demanda contrapartidas dos seus beneficiários.

Programas sociais que têm como marca a exigência de condicionalidades para transferir renda possuem o duplo objetivo de combater a pobreza e a desigualdade no curto prazo, provendo às famílias um benefício mínimo, além de procurar reduzir a transmissão intergeracional da pobreza, via incentivo à acumulação de capital humano das futuras gerações, através das adequações exigidas dos seus beneficiários (Fiszbeins e Schady, 2009).

\subsection{Focalização}

No que tange a cobertura da população alvo a ser trabalhada nos programas sociais, dados os critérios de elegibilidade do PBF, a análise de sua focalização permite avaliar em que medida a população alvo do programa está sendo atendida. Barros et al. (2010) ensina que um programa bem focalizado é aquele com maior incidência de beneficiários nos centésimos mais pobres da distribuição de renda de uma população.

Diversos autores apontam boa focalização do programa e evidenciam sua importância para a melhoria dos indicadores sociais brasileiros nos últimos anos. Estudo feito por Tavares et

\footnotetext{
${ }^{5}$ Soares et al. (2009) destaca que o PETI só foi integrado ao PBF em 2005.
} 
Artigo original

Hegemonia - Revista Eletrônica de Relações Internacionais do Centro Universitário Unieuro ISSN: 1809-1261

UNIEURO, Brasília, número 20, Janeiro-Junho de 2016, pp. 120-147.

al. (2009) com base na PNAD de 2004 observou que, a nível nacional, mais da metade (53\%) dos

beneficiários pertencia ao público alvo do programa. Sinalizou, ainda, que nos estados onde a pobreza era mais severa, o grau de focalização tinha sido mais elevado.

Estudo de Soares el al. (2009), baseado nas PNADs entre 2004 e 2006, afirma que o programa contava com alto grau de focalização naquele período. Segundo os autores, este fato é explicado por conta dos critérios de elegibilidade do PBF, que se baseiam na renda familiar per capita e na presença de crianças e jovens na família. Como estes estão representados entre os que possuem a menor renda originária do trabalho, o PBF acaba por atingir, de fato, os que detêm maior insuficiência de rendimentos.

Podemos finalizar citando Soares et al. (2010, p.40), que constata: “[...] a ótima focalização do programa. Qualquer que seja o ano, a imensa maioria ( $80 \%$ ou mais) dos benefícios do Bolsa Família vai para os $40 \%$ mais pobres."

\subsection{Otimização da focalização}

O sucesso de um programa social pode ser medido pela eficácia de seus resultados. Medeiros et al. (2007) observa que, em 2006, o PBF estava cumprindo seus propósitos e sendo efetivamente direcionado à população mais pobre. Entretanto, sugere que, para minimizar os erros de focalização, dois fatores deveriam ser considerados: flutuação de renda dos beneficiários ao longo do tempo e os erros inseparáveis à seleção das famílias ao programa.

Soares et al. (2009) defende que a volatilidade de renda das famílias beneficiadas pelo PBF deve ser levada em consideração para que o programa atinja melhores graus de focalização. Argumenta que quando há um acréscimo nos rendimentos (por exemplo, se um membro do domicílio aumenta a renda por meio do trabalho), alocando a família fora dos limites financeiros elegíveis, e esta é desvinculada do programa, há perda de focalização daquele. Isto porque o 
Artigo original

Hegemonia - Revista Eletrônica de Relações Internacionais do Centro Universitário Unieuro

ISSN: 1809-1261

UNIEURO, Brasília, número 20, Janeiro-Junho de 2016, pp. 120-147.

progresso financeiro pode ser temporário, e após um período, há possibilidades de que a renda

per capita retorne ao antigo patamar em que estava quando a família ainda era elegível a receber benefício.

Deste modo, Soares et al.(2009) também salienta que um choque positivo de renda originária do trabalho de algum membro da família não deve ser levado em consideração para a exclusão automática do PBF. Este incremento financeiro está sujeito à alta taxa de rotatividade do mercado de trabalho, onde os mais pobres sofrem maior insegurança, podendo deixar subitamente de compor a renda da família. Defende que enquanto houver vulnerabilidade das famílias beneficiadas a este mercado, o auxílio deveria ser mantido.

No que tange aos erros inerentes à seleção das famílias, Soares et al.(2009) explica que a expansão da cobertura do programa favorece a população mais pobre, mas à custa de uma piora da focalização, tornando-se cada vez mais difícil evitar que famílias não elegíveis sejam incluídas entre os beneficiários. Todavia, Medeiros et al. (2007) defende que este problema (erro de inclusão) deve ser tratado em segundo plano, visto que problema maior se encontra na eliminação de famílias (erro de exclusão) que, de fato, atendem aos critérios, devido à inclusão errônea de outras com renda per capita acima dos limites. Soares et al. (2010) comenta a gravidade desses problemas:

O erro de exclusão é muito mais preocupante do que o erro de inclusão e representa a dificuldade do programa em atingir parte das famílias pobres. Um erro de inclusão indevida leva, no máximo, ao desperdício de um benefício modesto. Já o erro de exclusão indevida pode levar ao abandono de uma família à beira da fome. (SOARES, et al. 2005, p.42)

Isto posto, para otimização da focalização do PBF, os autores alertam que a prioridade deve ser a minimização dos erros de exclusão, pois os erros de inclusão só seriam realmente graves caso as famílias não pobres que estivessem recebendo os benefícios situassem-se muito distantes da linha de pobreza, o que, segundo eles, não ocorria a níveis preocupantes. 
Artigo original

Hegemonia - Revista Eletrônica de Relações Internacionais do Centro Universitário Unieuro

ISSN: 1809-1261

UNIEURO, Brasília, número 20, Janeiro-Junho de 2016, pp. 120-147.

\subsection{Progressividade ou regressividade das transferências}

$\mathrm{Na}$ literatura, há um extenso debate sobre o grau de progressividade ou regressividade da tributação. Analogamente, é possível empregar esta análise sobre as transferências de renda do governo para as pessoas, e, entre elas, a dos benefícios pagos pelo PBF.

Hoffman (2007) ensina que um benefício corresponde a um Imposto Negativo. Este último, proposto por Milton Friedman ${ }^{6}$, tem como fundamento a compensação financeira por parte do Estado aos trabalhadores com rendimentos familiares inferiores a um determinado limite. Essa compensação equivale à diferença entre a renda auferida e o limite pré-definido. Ou seja, da mesma maneira que as pessoas que ganham além de um certo patamar pagam uma proporção de seus rendimentos ao governo, na forma de imposto de renda, aquelas que ganham menos passariam a ter o direito de receber uma proporção daquela diferença.

Ainda segundo Hoffmann (2007), a análise da progressividade ou regressividade dos benefícios está associada à ideia de atenuar ou de agravar a desigualdade, respectivamente. Isto posto, o autor completa: "Um benefício progressivo contribui para reduzir a desigualdade, por ser proporcionalmente maior para os relativamente mais pobres” (2007, p. 185).

Nessa mesma linha de pensamento, Sátyro et al.(2009) afirma que o PBF conta com alto grau de progressividade, isto é, a maior parte das suas transferências chega aos mais pobres, sendo um dos principais causadores da distribuição mais igualitária de renda no Brasil.

\footnotetext{
${ }^{6}$ Ver Negative Income Tax, Milton Friedman (1968).
} 
Artigo original

Hegemonia - Revista Eletrônica de Relações Internacionais do Centro Universitário Unieuro ISSN: 1809-1261

UNIEURO, Brasília, número 20, Janeiro-Junho de 2016, pp. 120-147.

\subsection{Impactos distributivos}

De uma maneira geral, muitos estudos apontam a importância do PBF tanto na redução da pobreza quanto na queda recente da desigualdade da distribuição de renda brasileira. Em estudo de Soares et al. (2010), que analisou o período de 1999 a 2009, foi constatado que 16\% da redução da pobreza naqueles dez anos poderia ser atribuída ao PBF. A linha de pobreza utilizada foi de $\mathrm{R} \$ 100,00$ a preços de janeiro de 2004. A participação do Programa na queda da extrema pobreza naquele período foi ainda maior, atingindo $32 \%$ de contribuição, quase um terço do total. Foram considerados como extremamente pobres as famílias com renda per capita de até $\mathrm{R} \$ 50,00$.

Ainda segundo os autores, entre períodos menores a participação do programa na redução dos níveis de pobreza é ainda mais visível. Entre 2003 e 2005, a pobreza caiu 4,2\% e a pobreza extrema caiu 2,7\%. A parcela atribuída à participação do PBF nesses índices foi de 17\% na pobreza e 40\% na extrema pobreza. No período de 2007 a 2009 o programa foi responsável por quase $60 \%$ na redução da pobreza, e contribuiu para que a extrema pobreza continuasse caindo durante a crise de 2008, quando de fato, a renda do trabalho dos pobres declinou.

Entre 1999 e 2009, o coeficiente de Gini (uma das melhores e mais usadas medidas de desigualdade $)^{7}$ caiu de 0,592 para 0,540 . Os benefícios do PBF responderam por $15 \%$ da queda observada, mesmo representando menos de $1 \%{ }^{8}$ do total da renda das famílias, consagrando, de fato, o seu potencial para promover a queda da desigualdade de renda existente no Brasil.

\footnotetext{
${ }^{7} \mathrm{O}$ índice de Gini varia de 0 a 1, com 0 representando a renda completamente distribuída (igualdade perfeita) e 1 com a renda completamente concentrada.

${ }^{8}$ Mais precisamente, $0,7 \%$.
} 
Artigo original

Hegemonia - Revista Eletrônica de Relações Internacionais do Centro Universitário Unieuro

ISSN: 1809-1261

UNIEURO, Brasília, número 20, Janeiro-Junho de 2016, pp. 120-147.

\section{CARACTERISTICAS DO PROGRAMA BOLSA FAMÍLIA}

A seguir apresentamos algumas das principais características do programa bolsa família $(\mathrm{PBF})$.

\subsection{Benefícios}

O PBF prevê benefícios financeiros às famílias em situação de pobreza e de extrema pobreza. As famílias têm liberdade na aplicação do dinheiro recebido e podem permanecer no programa enquanto houver manutenção dos critérios de elegibilidade. O Tabela 1 abaixo apresenta a evolução do teto da renda familiar mensal per capita que garante a elegibilidade ao programa.

Tabela 1 - Evolução do teto da renda mensal familiar per capita

\begin{tabular}{ccc}
\hline Ano & Extremamente pobres & Pobres \\
\hline 2004 & $\mathrm{R} \$ 50,00$ & $\mathrm{R} \$ 100,00$ \\
2005 & $\mathrm{R} \$ 50,00$ & $\mathrm{R} \$ 100,00$ \\
2006 & $\mathrm{R} \$ 60,00$ & $\mathrm{R} \$ 120,00$ \\
2007 & $\mathrm{R} \$ 60,00$ & $\mathrm{R} \$ 120,00$ \\
2008 & $\mathrm{R} \$ 60,00$ & $\mathrm{R} \$ 120,00$ \\
2009 & $\mathrm{R} \$ 70,00$ & $\mathrm{R} \$ 140,00$ \\
2010 & $\mathrm{R} \$ 70,00$ & $\mathrm{R} \$ 140,00$ \\
2011 & $\mathrm{R} \$ 70,00$ & $\mathrm{R} \$ 140,00$ \\
\hline
\end{tabular}

Fonte: Elaboração própria dos autores com base nos dados do MDS.

Famílias em situação de extrema pobreza têm direito ao benefício básico independentemente da composição familiar, enquanto as famílias em situação de pobreza 
Artigo original

Hegemonia - Revista Eletrônica de Relações Internacionais do Centro Universitário Unieuro ISSN: 1809-1261

UNIEURO, Brasília, número 20, Janeiro-Junho de 2016, pp. 120-147.

recebem somente os benefícios variáveis. Estes exigem que haja entre os membros da família crianças ou adolescentes de até 17 anos, gestantes e/ou nutrizes.

São três tipos de benefícios, que variam de acordo com a renda per capita e a composição familiar (número e idade dos filhos, presença de gestantes e/ou nutrizes). São eles:

- Benefício Básico: concedido às famílias extremamente pobres, independente da composição familiar.

- Benefício Variável: concedido às famílias em situação de extrema pobreza ou pobreza, caso existam em seu âmbito crianças de 0 a 15 anos, gestantes e/ou nutrizes.

- Benefício Vinculado ao Adolescente (BVJ): concedido às famílias em situação de extrema pobreza ou pobreza, caso existam em sua composição adolescentes entre 16 e 17 anos.

O Quadro 1 abaixo exibe a valores referentes aos benefícios em 2004 e em 2011, além dos limites que uma família elegível poderia receber de cada um deles:

Quadro 1 - Evolução dos valores e limites dos benefícios do PBF

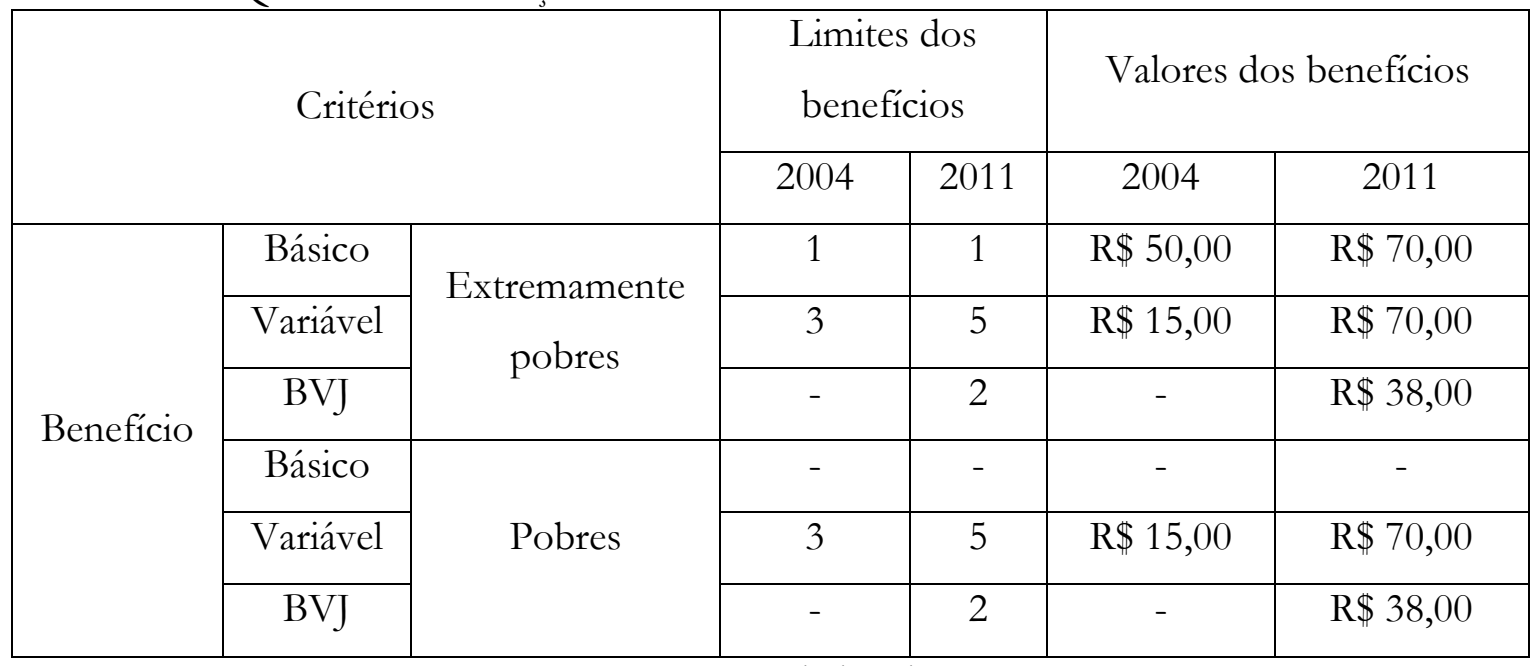

Fonte: Elaboração própria dos autores com base nos dados do MDS. 
Artigo original

Hegemonia - Revista Eletrônica de Relações Internacionais do Centro Universitário Unieuro

ISSN: 1809-1261

UNIEURO, Brasília, número 20, Janeiro-Junho de 2016, pp. 120-147.

\subsection{Condicionalidades}

As condicionalidades exigidas pelo PBF são administradas de forma a viabilizar o acesso a direitos sociais básicos por parte da população carente. Desta forma, as exigências destas contrapartidas buscam atingir objetivos de inserção no que tange à educação e saúde das famílias beneficiadas, além de significar compromisso e responsabilidade de quem recebe o benefício. Têm como objetivo ainda estimular a emancipação sustentada das famílias que vivem em situação de pobreza e extrema pobreza, construindo meios e condições para que elas possam sair da situação de vulnerabilidade em que se encontram (MDS, 2012).

A primeira condicionalidade é o acompanhamento de saúde. As famílias beneficiárias assumem o compromisso de acompanhar o cartão de vacinação e o crescimento e desenvolvimento nutricional das crianças menores de 7 anos. As mulheres com faixa etária entre 14 e 44 anos também devem fazer o acompanhamento e, se gestantes ou nutrizes, devem realizar exames pré-natal, além do acompanhamento da sua saúde e do bebê (pós-natal) (MDS, 2012).

No âmbito da educação e ensino, as condicionalidades visam promover o desenvolvimento da capacidade intelectual, garantindo o acesso educacional aos indivíduos membros da família em idade escolar. Desta forma, é exigido que crianças e adolescentes entre 6 e 15 anos estejam devidamente matriculadas e com frequência mínima de 85\% da carga horária mensal. Já os estudantes entre 16 e 17 anos devem ter frequência de, no mínimo, 75\% (MDS, 2012).

Em caso de descumprimento destas condicionalidades, o poder público identifica os motivos da não realização através de acompanhamento gerencial, e busca orientar as famílias em maior vulnerabilidade a superar as dificuldades enfrentadas. Esgotadas as chances de reverter o 
Artigo original

Hegemonia - Revista Eletrônica de Relações Internacionais do Centro Universitário Unieuro

ISSN: 1809-1261

UNIEURO, Brasília, número 20, Janeiro-Junho de 2016, pp. 120-147.

descumprimento das condicionalidades, a família pode ter o benefício bloqueado, suspenso ou

cancelado (MDS, 2012).

3.3. Custos e cobertura

Segundo a Matriz de Informação Social do Ministério de Desenvolvimento Social e Combate à Fome (MDS), o PBF atendia, em 2004, 6,57 milhões de famílias em todo o território nacional, ao custo de R $\$ 3,79$ bilhões. Em 2011, estes números alcançaram 13,35 milhões de famílias beneficiadas, custando o equivalente a $\mathrm{R} \$ 17,36$ bilhões aos cofres públicos.

A região Nordeste concentra a maior quantidade de benefícios pagos pelo PBF, equivalente a 50,53\% do total em 2004 e 51,12\% em 2011. Com mais de 3,32 milhões de famílias atendidas em 2004, seu custo naquele ano foi de R 2,17 bilhões. Em 2011 estes números evoluíram para 6,83 milhões de famílias e R \$ 8,99 bilhões.

A taxa média de crescimento da cobertura do PBF no Nordeste foi de $11,41 \%$ para o período entre 2004 - 2011. Dos nove estados o compõem, aqueles que tiveram maior expansão média da cobertura foram o Maranhão (14,34\%), Sergipe (12,99\%), Pernambuco (12,24\%) e Bahia (11,72\%), para o mesmo intervalo.

Em relação à evolução dos gastos com as transferências, o aumento médio foi de 22,73\% para toda a região. Sergipe apresentou a maior alta, com 25,71\%. Em seguida aparecem Pernambuco, Maranhão e Bahia, com 25,59\%, 25,39\% e 23,28\% respectivamente. 
Artigo original

Hegemonia - Revista Eletrônica de Relações Internacionais do Centro Universitário Unieuro ISSN: 1809-1261

UNIEURO, Brasília, número 20, Janeiro-Junho de 2016, pp. 120-147.

\subsection{PNAD}

Esta análise utilizou os dados das Pesquisas Nacionais por Amostra de Domićlíio (PNADs) de $2004^{9}$ e 2011 realizadas pelo Instituto Brasileiro de Geografia e Estatística (IBGE), filtrados para a região Nordeste. A pesquisa tem periodicidade anual e é a mais importante fonte de informações sobre a realidade social brasileira, sendo constantemente utilizada para análise de resultados de políticas públicas.

Conta com dois tipos de instrumentos de coleta, sendo eles: o questionário de domićlios e o questionário de pessoas. As perguntas cobrem áreas como características da unidade domiciliar, população, fecundidade, educação, migração, trabalho e rendimentos.

Como o foco deste estudo é avaliar o impacto do PBF na queda da pobreza e da desigualdade na região Nordeste, usamos para análise, principalmente, as perguntas referentes aos rendimentos das famílias. Para limpeza dos dados, incluímos na construção da base apenas os domicílios particulares permanentes. Foram desconsiderados os domicílios sem declaração de rendimento, isto é, aqueles em que algum dos moradores não informou o valor dos rendimentos recebidos em alguma das fontes de renda captadas pela PNAD. Além deste procedimento, também descartamos os moradores que declararam ser pensionistas, empregado doméstico ou parente de empregado doméstico. Todos os cálculos foram feitos usando os pesos das pessoas fornecidos pelo IBGE.

Consideramos a renda domiciliar per capita obtida somando todas as rendas disponíveis na PNAD, de todos os indivíduos no domićlio (exceto aqueles já citados), e dividindo pelo número de membros no mesmo domićlio (idem).

\footnotetext{
${ }^{9}$ Para 2004 foram usadas as projeções da população reponderadas que o IBGE divulgou junto com a PNAD de 2011.
} 
Artigo original

Hegemonia - Revista Eletrônica de Relações Internacionais do Centro Universitário Unieuro

ISSN: 1809-1261

UNIEURO, Brasília, número 20, Janeiro-Junho de 2016, pp. 120-147.

4. METODOLOGIA

4.1. Decomposição por fontes de renda

Para que os objetivos deste estudo fossem atingidos, utilizou-se metodologia proposta por Hoffman $(2004,2005)$ de decompor o índice de Gini conforme parcelas do rendimento domiciliar per capita (RDPC), a fim de analisar a contribuição desses componentes para a redução da desigualdade no Nordeste entre 2004 - 2011, com base nos dados da PNAD dos anos citados. O autor explica:

Quando o rendimento é decomposto em parcelas, podemos calcular a razão de concentração de cada parcela, que mede o grau de desigualdade da distribuição daquele tipo de rendimento, considerando a ordenação das pessoas conforme o rendimento domiciliar per capita. (HOFFMANN, 2005, p.2)

Desta forma, as diversas fontes de renda foram agregadas em seis parcelas:

i. $\quad \mathrm{TP}$ - renda proveniente do trabalho principal;

ii. OTTR - renda do trabalho secundário e outros trabalhos;

iii. $\quad$ AP - renda de aposentadorias e pensões oficiais, ou seja, aquelas pagas pelo governo federal ou por instituto de previdência, e outras aposentadorias e pensões, de cunho privado;

iv. $\quad$ PS - renda de programas sociais, que é uma aproximação para as transferências do PBF;

v. JUR - renda de juros, que é uma aproximação para os rendimentos financeiros (aluguéis, juros e dividendos $)^{10}$

vi. OUTROS - outros rendimentos, que incluem doações, abono de permanência.

Os dados da PNAD, no entanto, apresentam limitações. O questionário básico não inclui perguntas que captem, separadamente, a renda de programas sociais. O IBGE vem adotando procedimento de classificar esse tipo de transferências no quesito "Outros rendimentos".

\footnotetext{
${ }^{7}$ Os itens iv. e v. foram calculados a partir da mesma variável “Outros rendimentos” do questionário básico da PNAD.
} 
Artigo original

Hegemonia - Revista Eletrônica de Relações Internacionais do Centro Universitário Unieuro ISSN: 1809-1261

UNIEURO, Brasília, número 20, Janeiro-Junho de 2016, pp. 120-147.

Entretanto, este item se trata de um agregado de rendas díspares, que também investiga renda de juros de caderneta de poupança ou de outras aplicações e dividendos.

Dadas essas circunstâncias, faz-se necessário um tratamento para extrair a corretamente as rendas de juros e as rendas de programas sociais. Hoffmann (2005) ensina que é de se supor que os rendimentos financeiros sejam apropriados pelos relativamente mais ricos, enquanto que os relativamente mais pobres apoderam-se dos rendimentos provenientes de programas sociais.

Isto posto, para distinguir estes dois tipos de rendimentos, seguiu-se procedimento adotado em Hoffmann $(2006)^{11}$, de distribuição da renda domiciliar em estratos da população. Isto permitiu avaliar qual o percentual da renda é apropriada pelos mais ricos e mais pobres, e, assim, fazer a separação entre rendimentos financeiros e rendimentos das transferências governamentais.

4.2. Decomposição do índice de Gini das medidas de desigualdade

Nesta subseção apresentamos a decomposição das medidas de desigualdade proposta por Hoffmann (2006), que é usualmente empregada para se avaliar a contribuição das principais fontes de renda na desigualdade, por meio da decomposição do índice de Gini. As parcelas que serão analisadas são as citadas na subseção anterior.

Seja $x_{i}$ a renda domiciliar per capita da $i$-ésima pessoa, com $i=1, \ldots, n$, e $n$ indicando o tamanho da população. Os rendimentos estão ordenados de maneira que:

$$
x_{1} \leq x_{2} \leq \cdots \leq x_{n}
$$

Sendo $\mu$ a média dos $x_{i}$, as coordenadas da curva de Lorenz são dadas por: $p_{i}=\frac{i}{n}$

$\mathrm{e}$

$\phi_{i}=\frac{1}{n \mu} \sum_{j=1}^{i} x_{j}(3)$

\footnotetext{
${ }^{11}$ Para uma discussão mais pormenorizada, ver seção 2 de Hoffmann (2006).
} 
Artigo original

Hegemonia - Revista Eletrônica de Relações Internacionais do Centro Universitário Unieuro

ISSN: 1809-1261

UNIEURO, Brasília, número 20, Janeiro-Junho de 2016, pp. 120-147.

onde a área entre a curva de Lorenz e a linha de perfeita igualdade é representada por $\phi=p$.

O índice de Gini $(G)$ da distribuição pode variar de 0 a menos de 1 e é calculado por meio da seguinte expressão:

$$
G=\frac{2}{n} \sum_{i=1}^{n-1}\left(p_{i}-\phi_{i}\right)(4)
$$

Podemos decompor as mudanças do índice em duas partes: o coeficiente de concentração e o peso de cada parcela da renda em relação ao rendimento domiciliar per capita. Assim, admitese que a renda $x_{i}$ é formada por $k$ parcelas:

$$
x_{i}=\sum_{h=1}^{k} x_{h i}(5)
$$

Analiticamente, se $m_{k}$ for o peso da parcela $k$ na renda total $x_{i}$ então:

$$
\sum m_{k}=1(6)
$$

Sendo $\beta$ a área entre a curva de Lorenz e o eixo das abscissas, o índice de Gini pode ser alcançado de

$$
G=1-2 \beta(7)
$$

Assim, o coeficiente de concentração de cada parcela $x_{h i}$ será:

$$
C_{h}=1-2 \beta_{h}(8)
$$

com $-1<C_{h}<1$.

Sendo $\beta_{h}$ a área entre a curva de concentração da parcela $x_{h i}$ (que mostra como a proporção acumulada das parcelas varia de acordo com a proporção acumulada da população, de acordo com ordenamento feito em (1)) e o eixo das abscissas.

Dessa maneira, o índice de Gini da distribuição de renda pode ser dividido em $k$ componentes, que correspondem às seis parcelas do rendimento domiciliar que dividimos na subseção anterior.

Sendo $\varphi_{h}$ a participação da $h$-ésima parcela no rendimento total, e $C_{h}$ é o seu respectivo coeficiente de concentração, pode-se demonstrar que o índice de Gini é a razão de concentração do próprio rendimento domiciliar per capita:

$$
G=\sum_{h=1}^{6} \varphi_{h} C_{h}(9)
$$

\subsection{Impactos na desigualdade}

Para decompor o índice de Gini em dois anos distintos $(2004=1$ e $2011=2)$ e obter uma expressão dinâmica, fazemos:

$$
\begin{aligned}
G_{1}= & \sum_{h=1}^{6} \varphi_{1 h} C_{1 h}(10) \\
G_{2}= & \sum_{h=1}^{6} \varphi_{2 h} C_{2 h}(11) \\
& \text { A variação no índice entre esses dois anos será: }
\end{aligned}
$$

$$
\Delta G=G_{2}-G_{1}=\sum_{h=1}^{6}\left(\varphi_{2 h} C_{2 h}-\varphi_{1 h} C_{1 h}\right)(12)
$$

Após somar e subtrair $\varphi_{1 h} C_{2 h}$ e fatorar, arranjamos:

$\Delta G=\sum_{h=1}^{6}\left(C_{1 h} \Delta \varphi_{h}+\varphi_{2 h} \Delta C_{h}\right)(13)$

$\operatorname{com} \Delta \varphi_{h}=\varphi_{2 h}-\varphi_{1 h}$ e $\Delta C_{h}=C_{2 h}-C_{1 h}$.

$\mathrm{O}$ primeiro termo da equação representa o Efeito Composição, que se associa à uma mudança no peso relativo de cada fonte em relação à renda domiciliar total, com suas razões de concentração mantidas fixas. Já o segundo termo é o Efeito Concentração, uma vez que a mudança ocorre na concentração de cada fonte de renda, mantendo-se constante o peso (participação) na renda total. Soares et al. (2010) explica: 
Artigo original

Hegemonia - Revista Eletrônica de Relações Internacionais do Centro Universitário Unieuro

ISSN: 1809-1261

UNIEURO, Brasília, número 20, Janeiro-Junho de 2016, pp. 120-147.

"[...] uma diminuição da concentração de uma dada renda contribui para a igualdade e um

aumento no peso de uma renda menos concentrada que o Gini, também. Inversamente, um aumento na concentração de qualquer renda contribui para a desigualdade e também um aumento no peso de uma renda mais concentrada que o Gini.”

\subsection{Pobreza}

Um dos principais efeitos esperados do PBF é que contribua para a redução da pobreza. Há várias metodologias para decompor as variações nos índices de pobreza, entretanto, nos limitamos neste trabalho a analisar a redução através de uma abordagem mais comum (e simplificada), formalizada por Foster et al. (1981).

A abordagem consiste em analisar o percentual de pobres em uma dada população em dois períodos distintos. O indicador que capta esta redução é a taxa de pobreza, razão entre o número de pobres e a população total. Esta medida é a mais relevante, pois faz a sociedade caminhar rumo à erradicação da pobreza (Soares et al., 2010)

Para fins de cálculo, a linha de pobreza empregada nas análises foi de $\mathrm{R} \$ 140,00$ per capita na PNAD de 2011. A escolha foi feita com base nos critérios de elegibilidade do PBF para aquele ano $^{12}$.

\section{RESULTADOS}

A tabela 2 apresenta a decomposição do índice de Gini conforme as seis fontes do rendimento domiciliar per capita. Avaliaremos a seguir o comportamento de seus pesos e coeficientes de concentração na renda total.

\footnotetext{
${ }^{12}$ Em 2004 utilizamos os mesmos valores, deflacionados pelo Índice Nacional de Preços ao Consumidor (INPC).
} 
Hegemonia - Revista Eletrônica de Relações Internacionais do Centro Universitário Unieuro ISSN: 1809-1261

UNIEURO, Brasília, número 20, Janeiro-Junho de 2016, pp. 120-147.

Tabela 2 - Decomposição do Índice de Gini em fontes da RDPC

\begin{tabular}{|c|c|c|c|}
\hline Estatística & Renda & 2004 & 2011 \\
\hline Índice de Gini $(G)$ & RDPC & 0,5814 & 0,5430 \\
\hline \multirow{6}{*}{$\begin{array}{l}\text { Razão de concentração } \\
\qquad\left(C_{h}\right)\end{array}$} & TP & 0,5768 & 0,5603 \\
\hline & OTTR & 0,7770 & 0,7937 \\
\hline & $\mathrm{AP}$ & 0,6328 & 0,5665 \\
\hline & PS & $-0,0913$ & $-0,1755$ \\
\hline & JUR & 0,8660 & 0,8623 \\
\hline & Outros & 0,4017 & 0,2917 \\
\hline \multirow{6}{*}{$\begin{array}{l}\text { Participação no rendimento } \\
\qquad\left(\varphi_{h}\right) \%\end{array}$} & $\mathrm{TP}$ & 0,6695 & 0,6770 \\
\hline & OTTR & 0,0443 & 0,0343 \\
\hline & $\mathrm{AP}$ & 0,2317 & 0,2326 \\
\hline & PS & 0,0292 & 0,0402 \\
\hline & JUR & 0,0144 & 0,0124 \\
\hline & Outros & 0,0109 & 0,0036 \\
\hline
\end{tabular}

Fonte: Elaboração própria dos autores com dados nas PNADs de 2004 e 2011.

Nossos resultados mostram que entre 2004 e 2011 houve queda de 38,4 milésimos no coeficiente de Gini para a região Nordeste, apresentando, pois, uma redução de quase 4\%. Em 2011, as fontes com maiores participações no rendimento domiciliar per capita eram TP (trabalho principal), com $67,70 \%$ e AP (aposentadorias e pensões), com 23,26\%.

Agregando OT'TR (renda do trabalho secundário e outros trabalhos) à TP, é possível observar que os rendimentos provenientes do trabalho somavam mais de $70 \%$ da renda total nos dois anos observados. Vê-se a importância desse rendimento se ampliarmos a análise para suas respectivas razões de concentração. A renda do trabalho principal ficou mais progressiva (queda no coeficiente de concentração), e seus efeitos se multiplicam quando aliados ao seu peso na renda total.

As outras fontes representam as rendas não derivadas do trabalho. Verifica-se que o peso das aposentadorias e pensões manteve-se relativamente estável nos dois anos. Mudança maior 
Artigo original

Hegemonia - Revista Eletrônica de Relações Internacionais do Centro Universitário Unieuro

ISSN: 1809-1261

UNIEURO, Brasília, número 20, Janeiro-Junho de 2016, pp. 120-147.

incidiu na concentração desse tipo de rendimento. Esta caiu de 0,6328 para 0,5665 , o que pode ser reflexo das políticas de valorização do salário mínimo durante o período ${ }^{13}$.

A concentração dos rendimentos financeiros (JUR) foi reduzida, porém, seu peso na renda total também diminui entre os dois anos, o que não resulta em grandes mudanças na desigualdade.

A participação da renda proveniente de programas sociais (na nossa análise, a do PBF) apresentou aumento de pouco mais de 1\%, passando de 2,92\% em 2004 para 4,02\% em 2011. O sinal negativo à frente da razão de concentração do PBF representa o alto grau de progressividade do benefício.

5.1. Impactos na desigualdade

A tabela 3 a seguir exibe os impactos de cada fonte de renda para a queda da desigualdade.

Tabela 3 - Contribuição para a queda da desigualdade

\begin{tabular}{|c|c|c|c|c|c|}
\hline & Renda & 2004 & 2011 & $\Delta$ & $\% G$ \\
\hline \multirow{7}{*}{$\begin{array}{l}\text { Parcela do } \\
\text { índice de Gini } \\
\left(\varphi_{h} C_{h}\right)\end{array}$} & $G$ & 0,5814 & 0,5430 & 0,0384 & $100 \%$ \\
\hline & TP & 0,3861 & 0,3793 & 0,0068 & $18 \%$ \\
\hline & OTTR & 0,0344 & 0,0272 & 0,0072 & $19 \%$ \\
\hline & $\mathrm{AP}$ & 0,1467 & 0,1317 & 0,0149 & $39 \%$ \\
\hline & PS & $-0,0027$ & $-0,0071$ & 0,0044 & $11 \%$ \\
\hline & JUR & 0,0125 & 0,0107 & 0,0018 & $5 \%$ \\
\hline & Outros & 0,0044 & 0,0011 & 0,0033 & $9 \%$ \\
\hline
\end{tabular}

Fonte: Elaboração própria dos autores com dados nas PNADs de 2004 e 2011.

A maior parte da redução da desigualdade do rendimento domiciliar no Nordeste entre 2004 e 2011 está associada à parcela AP (aposentadorias e pensões), com 39\% de participação. Este resultado representa o Efeito Concentração, uma vez que se observou constante o peso da

\footnotetext{
${ }^{13}$ Grande parte das Aposentadorias e Pensões captadas pela PNAD são do tipo “Oficiais”, ou seja, aquelas pagas pelo INSS, diretamente atreladas ao salário mínimo.
} 
Artigo original

Hegemonia - Revista Eletrônica de Relações Internacionais do Centro Universitário Unieuro

ISSN: 1809-1261

UNIEURO, Brasília, número 20, Janeiro-Junho de 2016, pp. 120-147.

parcela na renda entre os dois anos, porém, com mudanças relevantes em sua razão de concentração.

Em seguida, 37\% da redução total é devida ao mercado de trabalho, somando-se a participação das rendas do trabalho principal (TP) à dos trabalhos secundários e de outros trabalhos (OTTR). Esse resultado é previsível, dado que as duas fontes somadas correspondem a mais de dois terços da renda das famílias.

A surpresa ficou a cargo das transferências do PBF, respondendo por $11 \%$ da queda da desigualdade. Sua contribuição é observada, principalmente, no Efeito Composição, visto que o peso do programa no rendimento domiciliar aumentou.

\subsection{Impactos na pobreza}

O progresso no combate à pobreza no período analisado foi considerável. Em 2011, 11 milhões (ou 22,39\% da população) de nordestinos sobreviviam com renda domiciliar per capita inferior a $\mathrm{R} \$ 140,00$ mensais, linha de elegibilidade ao PBF. Sete anos antes, em 2004, deflacionando o rendimento adotado, havia o dobro de pessoas vivendo abaixo dessa mesma linha de pobreza, mais de 22 milhões de pessoas (ou 44,76\% da população). A queda na taxa observada foi de $22,40 \%$.

A renda deste estrato mais pobre da população apresenta diferenças significativas em relação aos percentuais da região como um todo. A tabela 4 a seguir exibe esses resultados: 
Artigo original

Hegemonia - Revista Eletrônica de Relações Internacionais do Centro Universitário Unieuro ISSN: 1809-1261

UNIEURO, Brasília, número 20, Janeiro-Junho de 2016, pp. 120-147.

Tabela 4 - Participação por fontes de renda $(\mathrm{RDPC} \leq \mathrm{R} \$ 140,00)$

\begin{tabular}{cccc}
\hline Estatística & Renda & 2004 & 2011 \\
\hline & RDPC & 1,000 & 1,000 \\
Participação no rendimento & TP & 0,696 & 0,581 \\
$\left(\varphi_{h}\right) \%$ & OTTR & 0,022 & 0,013 \\
& AP & 0,134 & 0,095 \\
& PS & 0,125 & 0,299 \\
& JUR & 0,001 & 0,001 \\
& Outros & 0,022 & 0,011 \\
\hline
\end{tabular}

Fonte: Elaboração própria dos autores com dados nas PNADs de 2004 e 2011.

É possível observar que em 2004, os rendimentos oriundos do trabalho (TP + OTTR) contribuíam com quase $72 \%$ da renda total. Entre os rendimentos não provenientes do trabalho, naquele ano, aposentadorias e pensões (AP) e programas sociais (PS) representavam 26\% do total, com $13,4 \%$ e $12,5 \%$ respectivamente. As parcelas remanescentes (juros (JUR) e outros rendimentos (Outros)) reproduziam apenas 2,3\% das receitas.

Em 2011, este quadro sofreu expressivas mudanças. As remunerações do trabalho somavam aproximadamente $60 \%$ de participação na renda total, queda de quase $12,5 \%$ em relação a 2004. Já no que concerne aos outros rendimentos não derivados do trabalho, observouse o inverso: um acréscimo de $12,4 \%$ em peso no rendimento total.

Esta evolução foi puxada pela crescente participação dos programas sociais (PBF) na renda das famílias mais pobres. Sua contribuição aumentou $12,4 \%$ no período analisado, indo de 12,5\% em 2004 para quase 30\% em 2011. Dentre as fontes analisadas, esta foi a única que apresentou crescimento no período. Todas as outras tiveram diminuição em participação, exclusive juros, que se mantiveram estáveis.

\section{CONCLUSÃO}

É bastante expressivo o número das pessoas acometidas pelo mal da pobreza e da desigualdade no País. A fim de combater esse problema, foi criado o Programa Bolsa Família, a 
Artigo original

Hegemonia - Revista Eletrônica de Relações Internacionais do Centro Universitário Unieuro

ISSN: 1809-1261

UNIEURO, Brasília, número 20, Janeiro-Junho de 2016, pp. 120-147.

partir da junção de outros já existentes, tendo ele como principais objetivos amenizar as

condições de pobreza no curto prazo, via transferência direta de renda, e fomentar a acumulação

de capital humano no longo prazo, através do atendimento de condicionalidades específicas.

Neste sentido, pretendeu-se com o presente trabalho analisar em quanto o Programa Bolsa Família contribuiu para a redução da pobreza e da desigualdade da renda domiciliar per capita no Nordeste entre 2004 e 2011, uma vez que a região concentra mais da metade dos benefícios pagos.

Para tanto, seguiu-se metodologia proposta por Rodolfo Hoffmann, que decompõe o índice de Gini conforme parcelas do rendimento domiciliar per capita. Os dados utilizados foram os da Pesquisa Nacional por Amostra de Domicílios (PNAD) de 2004 e 2011.

Essa pesquisa, porém, apresenta algumas limitações quanto ao seu uso. Apesar de possuir questões que discriminem informações a respeito de aposentadorias e pensões públicas, a PNAD não informa, em detalhes, se o domicílio entrevistado recebe algum tipo de transferência de renda. O único item que se atém a este questionamento coleta, igualmente, informações acerca de rendimentos financeiros, provenientes de juros ou dividendos de aplicações financeiras, sem fazer qualquer distinção entre os dois tipos de renda.

Para contornar este obstáculo, usamos uma metodologia de imputações que permitiu identificar quais as rendas de origem financeira e quais de origem de transferências sociais (benefícios do $\mathrm{PBF}$ ), de acordo com estratos da população que se apropriam destes tipos de rendimento.

De posse dessas informações, investigamos o impacto de cada fonte de renda sobre a desigualdade e a pobreza no Nordeste. Os resultados indicaram queda no índice de Gini da região, de 0,5814 em 2004 para 0,5440 em 2011. As maiores contribuições para essa redução partiram das aposentadorias e pensões e da renda derivada do trabalho. Isto se deve, no caso das aposentadorias, à queda na sua razão de concentração, e nos rendimentos provenientes do 
Artigo original

Hegemonia - Revista Eletrônica de Relações Internacionais do Centro Universitário Unieuro ISSN: 1809-1261

UNIEURO, Brasília, número 20, Janeiro-Junho de 2016, pp. 120-147.

trabalho, ao grande peso destas fontes na renda total domiciliar. O Programa Bolsa Família, por sua vez, foi responsável por $11 \%$ da redução do Gini, revelando seu crescimento em termos de participação no rendimento.

O impacto sobre a pobreza também foi expressivo. À linha de pobreza de $\mathrm{R} \$ 140,00$ per capita, observou-se queda de $22,40 \%$ da proporção de pobres no período em análise, número esse que representa mais de 22 milhões de pessoas.

Ao considerarmos as famílias com renda inferior ao desta linha, podemos vislumbrar mais nitidamente o papel do Programa Bolsa Família em amenizar as condições de pobreza em que viviam. Em 2004, a renda total dessas famílias era composta por $71 \%$ de rendimentos derivados do trabalho. As outras parcelas somavam $29 \%$ da renda. A participação do Bolsa Família neste ano girava em torno de 13\%. Em 2011, este número subiu para quase 30\% da renda total, o único a apresentar aumento. A renda do trabalho contribuiu com $60 \%$ do montante, e os rendimentos de aposentadorias e pensões com 9,50\%, quase 4\% a menos que em 2004.

Das fontes que compõem a renda das famílias, as transferências de programas sociais (PBF) foram as que passaram por transformações mais significativas, tanto quanto ao seu peso na renda domiciliar quanto ao seu altíssimo grau de progressividade, claramente observado no seu coeficiente de concentração, principalmente entre as famílias com rendimentos muito baixos. Isto consolida, portanto, o papel relevante do Programa Bolsa Família para explicar a queda da pobreza e da desigualdade no Nordeste, observada entre 2004 e 2011.

\section{REFERÊNCIAS BIBLIOGRÁFICAS}

BARROS, R. P. de; CARVALHO, M.; FRANCO, S. O papel das transferências públicas na queda recente da desigualdade de renda brasileira. In: BARROS, R. P. de; FOGUEL, M. N.; 
Artigo original

Hegemonia - Revista Eletrônica de Relações Internacionais do Centro Universitário Unieuro

ISSN: 1809-1261

UNIEURO, Brasília, número 20, Janeiro-Junho de 2016, pp. 120-147.

ULYSSEA, G. Desigualdade de Renda no Brasil: uma análise da queda recente, v. 2. Brasília: Instituto

de Pesquisa Econômica Aplicada (IPEA), 2007.

BARROS, R. P. de; CARVALHO, M.; FRANCO, S.; MENDONÇA, R. A focalização do Programa Bolsa Família em perspectiva comparada. In: CASTRO, J. A. de; MODESTO, L. Bolsa Família 2003 - 2010: avanços e desafios, v.2. Brasília: Instituto de Pesquisa Econômica Aplicada (IPEA), 2010.

FISZBEIN, A.; SCHADY, N. Conditional Cash Transfers. Reducing Present and Future Poverty. Banco Mundial, 2009.

FOSTER, J.; GREER, J.; THORBECKE, E. A Class of Decomposable Poverty Measures. Department of Economics, Cornell University 1981. Working Paper n. 243.

HOFFMANN, R. As transferências não são a causa principal da redução da desigualdade. Econômica: revista de pós-graduação em Economia da UFF. Rio de Janeiro: UFF, v. 7, n. 2, p. 335-341, dezembro 2005.

. Medindo a regressividade das transferências. In: BARROS, R. P. de; FOGUEL, M. N.; ULYSSEA, G. Desigualdade de renda no Brasil: uma análise da queda recente, v. 2. Brasília: Instituto de Pesquisa Econômica Aplicada (IPEA), 2007.

- Transferências de renda e a redução da desigualdade no Brasil e cinco regiões entre 1997 - 2004. Econômica: revista de pós-graduação em Economia da UFF. Rio de Janeiro: UFF, v. 8, n. 1, p. 55 - 81, junho 2006.

Decomposition of Mehran and Piesch inequality measures by fator componentes and their application to the distribution of per capita hosehold income in Brazil. Brazilian Review of Econometrics. Rio de Janeiro, v. 24, n.1, p. 149 - 171, maio de 2004. 
Artigo original

Hegemonia - Revista Eletrônica de Relações Internacionais do Centro Universitário Unieuro

ISSN: 1809-1261

UNIEURO, Brasília, número 20, Janeiro-Junho de 2016, pp. 120-147.

MARINHO, E.; LINHARES, F.; CAMPELO, G. Os Programas de Transferência de Renda do

Governo Impactam a Pobreza no Brasil? Revista Brasileira de Economia (RBE), Rio de Janeiro, v.65 n.3 / p.267 - 288, julho - setembro 2011.

MDS; MINISTÉRIO DO DESENVOLVIMENTO SOCIAL E COMBATE À FOME Disponível em: < $\underline{w w w . m d s . g o v . b r}>$ - acessado em várias datas entre o abril e novembro de 2012.

MEDEIROS, M.; BRITTO, T.; SOARES, F. Target Cash Transfer Programmes in Brazil: BPC and Bolsa Família. Brasília: International Poverty Centre, 2008. Working Paper, n. 46.

NERI, M. Pobreza e políticas sociais na década da redução da desigualdade. Nueva Sociedad, especial em português. Buenos Aires, pp. 53-75, outubro 2007.

OSORIO, R. G.; SOARES, S.; SOUZA, P. H. G. F.. Erradicar a pobreza extrema: um objetivo ao alcance do Brasil. Instituto de Pesquisa Econômica Aplicada (IPEA), Brasília, Texto para Discussão n. 1.619, 2011.

PORTELA, D. Políticas de Distribuição de Renda no Brasil e o Bolsa-Família. Rio de Janeiro: EESP FGV. Texto para Discussão no 281, 2011.

ROCHA, S. Os "Novos" Programas de Transferências de Renda: impactos possíveis sobre a desigualdade no Brasil. In: BARROS, R. P. de; FOGUEL, M. N.; ULYSSEA, G. Desigualdade de Renda no Brasil: Uma Análise da Queda Recente - Vol. 2. Brasília: Instituto de Pesquisa Econômica Aplicada (IPEA), 2006.

. O Programa Bolsa Família: Evolução e Efeitos sobre a Pobreza. Economia e Sociedade, Campinas, v.20, n.1 (41), p. 113-139, abril 2011.

SÁTYRO, N.; SOARES, S. Análise do Impacto do Programa Bolsa Família e do Benefício de Prestação Continuada na Redução da Desigualdade nos Estados Brasileiros - 2004 a 2006. 
Artigo original

Hegemonia - Revista Eletrônica de Relações Internacionais do Centro Universitário Unieuro

ISSN: 1809-1261

UNIEURO, Brasília, número 20, Janeiro-Junho de 2016, pp. 120-147.

Instituto de Pesquisa Econômica Aplicada (IPEA), Rio de Janeiro, Texto para Discussão, n. $1435,2009$.

SOARES, S.; RIBAS, R. P.; SOARES, F. V. Focalização e cobertura do Programa Bolsa-Família: Qual o significado dos 11 milhões de famílias? Instituto de Pesquisa Econômica Aplicada (IPEA), Brasília, Texto para Discussão, n. 1396, 2009.

SOARES, S.; SOUZA, P. H. G. F.; OSÓRIO, R.G.; SILVEIRA, F.G. Os impactos do benefício do Programa Bolsa Família sobre a desigualdade e a pobreza. In: CASTRO, J. A. de; MODESTO, L. Bolsa Família 2003 - 2010: avanços e desafios, v.2. Brasília: Instituto de Pesquisa Econômica Aplicada (IPEA), 2010.

SOARES, S. Volatilidade de renda e a cobertura do Programa Bolsa Família. Instituto de Pesquisa Econômica Aplicada (IPEA), Rio de Janeiro, Texto para Discussão, n. 1459, 2009.

TAVARES, P. A.; PAZELLO, E. T.; FERNANDES, R.; CAMELO, R. S. Uma avaliação do Programa Bolsa Família: focalização e impacto na distribuição de renda e pobreza. Pesquisa e Planejamento Econômico, Rio de Janeiro, v. 39, p. 25-58, 2009.

SOARES, F. V.; SOARES, S.; MEDEIROS, M.; OSÓRIO, R. G. Programas de transferência de renda no Brasil: impactos sobre a desigualdade. Instituto de Pesquisa Econômica Aplicada (IPEA), Brasília, Texto para Discussão, n. 1228, 2006. 